Title: SUPERCONDUCTING CAVITIES FOR THE APT ACCELERATOR

\author{
Author(s): Frank L. Krawcyzk \\ Robert C. Gentzlinger \\ Brian Haynes \\ Debbie I. Montoya \\ Brian Rusnak \\ Alan H. Shapiro
}

\author{
LANSCE-1 \\ ESA-DE \\ LANSCE-9 \\ ESA-DE \\ LANSCE-1 \\ LANSCE-1
}

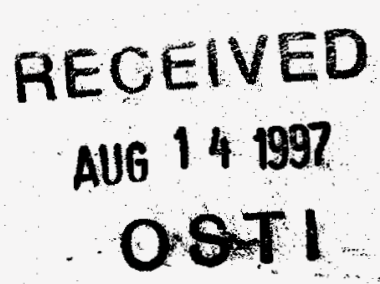

Submitted To: 1997 Particle Accelerator Conference

Vancouver, BC, Canada

May 12-16, 1997

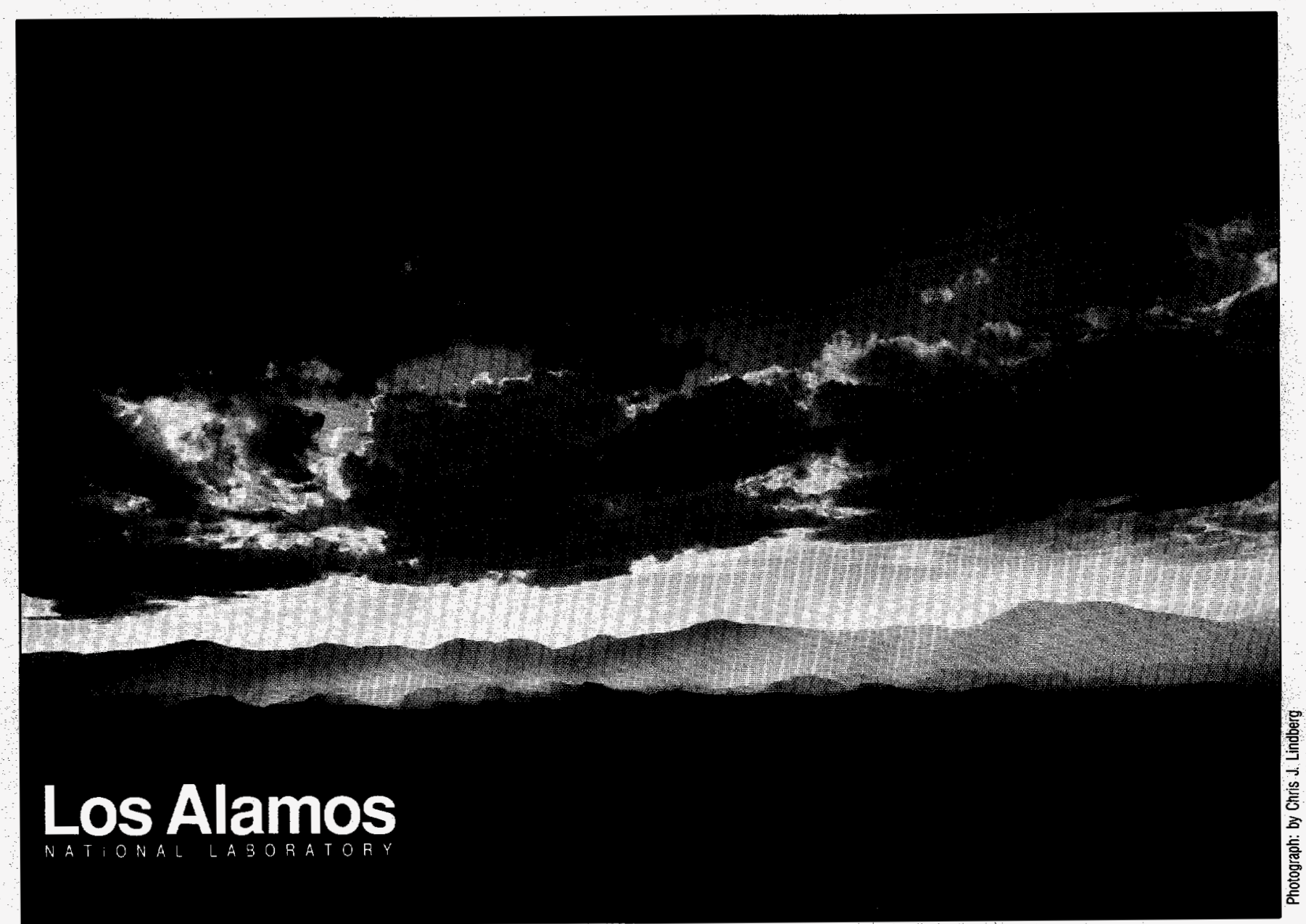

This is a preprint of a paper intended for publication in a journal or proceedings. Because changes may be made before publication, this preprim is made available with the understanding that it will not be cited or reproduced without the permission of the author. 


\title{
SUPERCONDUCTING CAVITIES FOR THE APT ACCELERATOR
}

\author{
Frank L. Krawczyk, Robert C. Gentzlinger, Brian Haynes, \\ Debbie I. Montoya, Brian Rusnak, Alan H. Shapiro, \\ LANL, LANSCE-1, MS H817, Los Alamos, NM 87545, USA
}

\section{Abstract}

The design of an Accelerator Production of Tritium (APT) facility being investigated at Los Alamos includes a linear accelerator using superconducting rf-cavities for the acceleration of a high-current $\mathrm{cw}$ proton beam. For electron accelerators with particles moving at the speed of light $(\beta \approx 1.0$ ), resonators with a rounded shape, consisting of ellipsoidal and cylindrical sections, are well established. They are referred to as "elliptical" cavities. For the APTdesign, this shape has been adapted for much slower proton beams with $\beta$ ranging from 0.60 to 0.94 . This is a new energy range, in which resonators of an elliptical type have never been used before. Simulations with the well-proven electromagnetic modeling tools MAFIA and SUPERFISH were performed. The structures have been optimized for their $\mathrm{If}$ and mechanical properties as well as for beam dynamics requirements. The TRAK.RF simulation code is used to investigate potential multipacting in these structures. All the simulations will be put to a final test in experiments performed on single cell cavities that have started in our structures laboratory.

\section{THE CAVITY SHAPE}

Superconducting 5-cell cavities at a $\pi$-mode frequency of $700 \mathrm{MHz}$ will be used for the major part of the APT facility. Due to the large velocity acceptance of these cavities only structures for two values of $\beta(0.64$ and 0.82$)$ are needed [1]. For each value of $\beta$ two different cross-sections have been determined, one for the mid-cells and one for the endcells, where compensation for field penetration into the attached beam-pipe is required. The choice of cavity shape made use of previous design experience at other labs, including Cornell, KEK and DESY [2]. Figure 1 shows the shape description for the chosen geometries. The shape of both the medium- $\beta(0.64)$ and the high- $\beta(0.82)$ cavities uses elliptically shaped noses, straight side walls and a circular dome. The upright nose ellipses have an aspect ratio of 2:1.

In a first step the shapes of the resonators were determined to minimize electric and magnetic peak surface fields as far as possible. The resulting cavity shapes turned out to lack sufficient mechanical stability. The medium$\beta$ structure needed stiffener support to sustain the vacuum load without yielding the material. Encouraged by recent cavity tests at JAERI for a $\beta=0.5$ superconducting cavity at $500 \mathrm{MHz}$ [3], we revisited the proposed cavity shapes and came up with an improved design that had less steep straight walls while maintaining good performance in terms of $\mathrm{rf}$ properties. Table 1 gives the relevant geo-

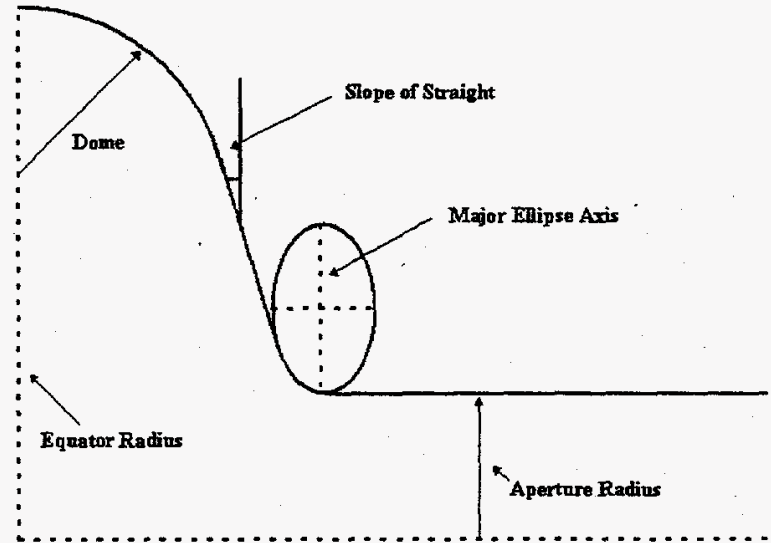

Figure 1: The describing parameters for the elliptical cavity shapes

metric parameters for all 4 shapes. The design procedure used fixed beam-pipe apertures based on beam-dynamics requirements, and fixed straight wall slopes (5 and 7 degrees in the first design and 10 degrees for both $\beta$ values in the final design). The elliptical noses were varied to find shapes with good peak-fields. The equator radius has been used to tune the cavities to the proper frequency. All other parameters fell into place automatically, assuming smooth transitions between the different parts of the cavity shapes.

\begin{tabular}{||l|c|c||c|c||}
\hline \hline$\beta$ & 0.64 & 0.64 & 0.82 & 0.82 \\
cell-type & mid & end & mid & end \\
\hline aperture[cm] & 6.5 & 6.5 & 8.0 & 8.0 \\
equator[cm] & 19.95 & 19.95 & 20.1 & 20.1 \\
major axis[cm] & 10.00 & 12.00 & 14.00 & 17.80 \\
slope[degree] & 10.00 & 10.00 & 10.00 & 10.00 \\
dome[cm] & 3.233 & 2.811 & 4.969 & 4.167 \\
cell-length[cm] & 13.71 & 13.71 & 17.56 & 17.56 \\
\hline
\end{tabular}

The end-cell geometries use inner half-cells identical to the mid-cells. The outer half-cell uses an equator radius and a cell length identical to the mid-cells, and the elliptical nose and the circular dome radii have been used to retune the cell to the desired $700 \mathrm{MHz}$.

The simulations have been done on single cavity cells, using $\pi$-mode boundary conditions at iris positions where neighboring cells exist. This was sufficient and more effcient in optimizing the cells for the accelerating mode. An investigation of the higher order mode (HOM) spectrum has been done for the full 5-cell geometry. These results will be reported in a separate contribution [4]. 


\section{DISCLAMMER}

Portions of this document may be illegible in electronic image products. Images are produced from the best available original document. 


\section{PERFORMANCE DATA}

The electromagnetic design of the cavity-cells has been done with MAFIA [5] and SUPERFISH [6]. From the electromagnetic fields, a set of secondary quantities has been derived that describe the if performance of these structures and their interaction with the beam. Table 2 gives the numbers for the most important quantities in a comparison of the mid-cells of the original design with the new shapes with larger side-wall slope.

\begin{tabular}{||l|c|c||c|c||}
\hline \hline$\beta$ & 0.64 & 0.64 & 0.82 & 0.82 \\
& new & old & new & old \\
\hline$Q_{0}\left[10^{10}\right]$ & 1.02 & 1.08 & 1.34 & 1.35 \\
Geometry Factor & 162 & 177 & 213 & 215 \\
$Z T^{2} / Q[\Omega / m]$ & 246 & 256 & 297 & 299 \\
$E_{p k} / E_{a}$ & 2.94 & 2.96 & 2.48 & 2.50 \\
$H_{p k} / E_{a}[\mathrm{G} / 5 \mathrm{MV} / \mathrm{m}]$ & 355 & 340 & 305 & 303 \\
$P_{\text {cav }}[\mathrm{W}]$ & 8.13 & 7.32 & 9.25 & 9.16 \\
\hline
\end{tabular}

The unloaded $Q_{0}$ assumes a surface resistance $\left(R_{s}\right)$ of 15.9 $n \Omega, Z T^{2} / Q$ is the ratio of effective shunt-impedance and $Q_{0}, E_{p k} / E_{a}$ and $H_{p k} / E_{a}$ give the ratio of peak surfacefields over accelerating gradient $\left(E_{a}=E_{0} T\right) . P_{c a v}$ is the power dissipated into the cavity by the accelerating mode. These power value reflect the dissipated power to achieve the average accelerating gradient $(5.16 \mathrm{MV} / \mathrm{m}$ at $\beta=0.64$ and $5.92 \mathrm{MV} / \mathrm{m}$ at $\beta=0.82$ ) for the TM010 $\pi$-mode. The transit time factor $(\mathrm{T})$ for a particle with the design- $\beta$ is 0.78 for all mid-cells.

In terms of the rf-parameters there is only a small difference in performance between both designs. The major driver for switching to the new shapes is the potential gain in structural stability. The increase of power deposited into the medium- $\beta$ cavities by $10 \%$ does not have a significant effect, since most of the accelerator consists of high- $\beta$ structures. The results for the end-cells are very similar, the only major difference being the transit time factors that are only 0.59 for the end-cells. This drop is partially compensated by a increase in $E_{0}$, so that $E_{0} T$ is only about $10 \%$ smaller than for the mid-cells.

\section{STRUCTURAL ANALYSIS}

Some preliminary structural analysis has been done on 2D models of the cavity shapes [7]. The shapes with the 10 degree slopes in the side-walls seem to be structurally more stable. Both shapes can withstand the vacuum loads without stiffening. The other consideration in applying stiffeners has to do with raising the resonant frequencies of the cavity mechanical modes to decrease the microphonic detuning sensitivity in operation. These studies are continuing. Even if these studies indicate that stiffeners are needed, they can probably be less complex than the conical stiffeners used for our first single-cell test cavity with the original steeper-sloped side-walls.

The choice for a 10-degree slope came from the preliminary $2 \mathrm{D}$ structural analysis. The medium- $\beta$ cavity showed a clear minimum in von-Mises stresses for a shape with a straight wall slope around 10 degrees (with and without constrained iris). For the high- $\beta$ cavity this minimum was not so clear, in fact even larger inclinations showed the sames stresses as the 10 degree slope did. But, for these larger inclinations the $\mathrm{rf}$ performance deteriorated strongly. The peak surface magnetic fields also increased, so did the frequency sensitivity with radius variations.

\section{MULTIPACTING}

Another concern is the potential for multipacting in these elliptical structures. So far experimental results for cavities with $\beta \approx 0.85$ at Cornell and SACLAY[8], as well as the above mentioned result from JAERI, indicate that there should be no principal problem for such geometries. A final resolution of the multipacting aspect will come from the laboratory tests on single-cell structures that is presently under way in Los Alamos. To support the experimental work, there is a numerical study under way at the University of New Mexico [9]. The TRAK_RF code is being used to investigate the single-cell geometries of both cavity shapes for multipacting susceptibility. First simulations indicate possible multipacting for values of $E_{a}$ between 2.8 and $4.5 \mathrm{MV} / \mathrm{m}$.

\section{SINGLE CELL CAVITY TEST}

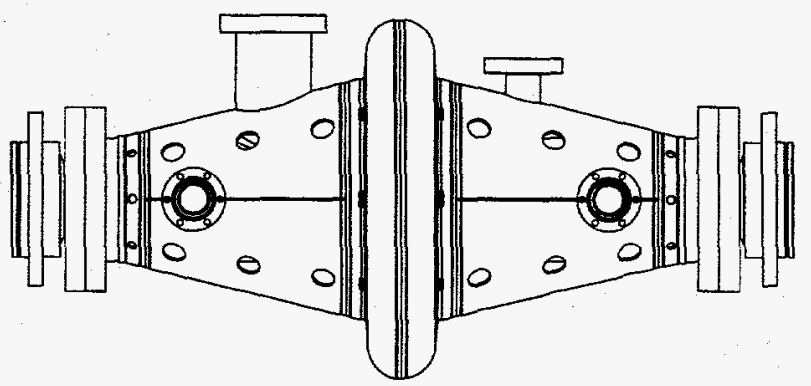

Figure 2: The tested $\beta=0.64$ single-cell cavity with stiffener

In the LANL superconducting structures laboratory we have completed assembly of the equipment for a vertical test of superconducting cavities at $700 \mathrm{MHz}$ under moderate rf power without beam. We are presently testing a single cell cavity at $\beta=0.64$ with the end-cell shape of the original choice of geometry. This is seen as a meaningful test of the operability of cavities as proposed for the APT facility, since it will provide data on the presence of multipacting in the medium- $\beta$ structures and it will also provide some field performance data. The end-cell geometry of a multi-cell cavity is more critical in determining performance. This is due to a) the wider elliptical nose that brings the opposing cavity walls closer together than in the mid-cells, and b) the steeper sloped side-walls result in opposing walls that are closer to parallel walls, which increases the potential for two-point multipacting. The cavity uses niobium with a $R R R=250$ and material of a thickness of $1 / 8$ ". These spec- 
ifications are identical to the ones for the planned acceleratòr facility.

\section{ACKNOWLEDGEMENTS}

This work is supported by the US Department of Energy.

\section{REFERENCES}

[1] G. Lawrence, T. Wangler, "Integrated Normalconducting/Superconducting High Power Proton Linac for APT", these proceedings

[2] D. Proch, (Ed.), "Proceedings of the 5th Workshop on RF Superconductivity", August 19-23, 1991, DESY M-92-01

[3] Nobuo Ouchi, JAERI, private communication

[4] Frank L. Krawczyk, "Higher Order Mode Analysis of the APT Superconducting Cavities", these proceedings

[5] M. Bartsch et al. "Solution of Maxwell's Equations", Computer Physics Comm. 72, 22-39 (1992)

[6] J. H. Billen and L. M. Young, "POISSON/SUPERFISH on PC Compatibles," Proceedings of the 1993 Particle Accelerator Conference, Vol. 2, p. 790.

[7] Dale Schrage, LANL, LANSCE-1, private communication

[8] Henry Safa, SACLAY and Hassam Padamsee, Cornell, private communication

[9] Stan Humphries, Daniel Rees, "TRAK_RF - Electromagnetic Field and Charged Particle Simulations in RF Devices", these proceedings

\section{DISCLAIMER}

This report was prepared as an account of work sponsored by an agency of the United States Government. Neither the United States Government nor any agency thereof, nor any of their employees, makes any warranty, express or implied, or assumes any legal liability or responsibility for the accuracy, completeness, or usefulness of any information, apparatus, product, or process disclosed, or represents that its use would not infringe privately owned rights. Reference herein to any specific commercial product, process, or service by trade name, trademark, manufacturer, or otherwise does not necessarily constitute or imply its endorsement, recom. mendation, or favoring by the United States Government or any agency thereof. The views and opinions of authors expressed herein do not necessarily state or reflect those of the United States Government or any agency thereof. 